\title{
Nuclear receptors and metabolism: from feast to famine
}

\author{
Suk-Hyun Hong • Maryam Ahmadian • Ruth T. Yu • \\ Annette R. Atkins • Michael Downes • Ronald M. Evans
}

Received: 19 December 2013 / Accepted: 18 February 2014 / Published online: 12 March 2014

(C) The Author(s) 2014. This article is published with open access at Springerlink.com

\begin{abstract}
The ability to adapt to cycles of feast and famine is critical for survival. Communication between multiple metabolic organs must be integrated to properly metabolise nutrients. By controlling networks of genes in major metabolic organs, nuclear hormone receptors (NHRs) play central roles in regulating metabolism in a tissue-specific manner. NHRs also establish daily rhythmicity by controlling the expression of core clock genes both centrally and peripherally. Recent findings show that many of the metabolic effects of NHRs are mediated through certain members of the fibroblast growth factor (FGF) family. This review focuses on the roles of NHRs in critical metabolic organs, including adipose tissue, liver and muscle, during the fed and fasted states, as well as their roles in circadian metabolism and downstream regulation of FGFs.
\end{abstract}

Keywords Circadian metabolism $\cdot$ FGFs $\cdot$ Glucose homeostasis $\cdot$ Nuclear receptors $\cdot$ Review

$\begin{array}{ll}\text { Abbreviations } \\ \text { BMAL1 } & \text { Brain and muscle ARNT-like 1 } \\ \text { CLOCK } & \text { Circadian locomotor output cycles kaput } \\ \text { CRY } & \text { Cryptochrome } \\ \text { ERR } \gamma & \text { Oestrogen-related receptor } \gamma \\ \text { FGF } & \text { Fibroblast growth factor } \\ \text { FXR } & \text { Farnesoid X receptor } \\ \text { LPL } & \text { Lipoprotein lipase } \\ \text { LXR } & \text { Liver X receptor }\end{array}$

S.-H. Hong $\cdot$ M. Ahmadian · R. T. Yu • A. R. Atkins $\cdot$ M. Downes $•$ R. M. Evans $(\square)$

Gene Expression Laboratory, Salk Institute for Biological Studies, La Jolla, CA 92037, USA

e-mail: evans@salk.edu

R. M. Evans

Howard Hughes Medical Institute, Salk Institute for Biological

Studies, La Jolla, CA, USA

$\begin{array}{ll}\text { NHR } & \begin{array}{l}\text { Nuclear hormone receptor } \\ \text { Gur77 }\end{array} \\ \text { gene nur/77-like receptor } \\ \text { PGC1 } \alpha & \text { PPAR } \gamma \text { co-activator } 1 \alpha \\ \text { PPAR } & \text { Peroxisome proliferator-activated receptor } \\ \text { REV-ERB } & \text { Reverse c-erbA } \\ \text { ROR } & \text { Retinoid orphan receptor } \\ \text { SCN } & \text { Suprachiasmatic nucleus } \\ \text { TZD } & \text { Thiazolidinedione } \\ \text { WAT } & \text { White adipose tissue }\end{array}$

\section{Introduction}

The ability to navigate through unpredictable environmental changes such as cycles of feast and famine is critical for the survival of an organism. In order to adapt to fluctuations in nutrient availability, communication between multiple metabolic organs must be integrated to properly metabolise carbohydrates, proteins and lipids. Dysregulation of these processes can have an impact on survival during a fast or lead to obesity and related pathologies, such as type 2 diabetes, in response to overnutrition. However, the underlying mechanisms that maintain metabolic balance during extremes of nutrient challenge remain poorly understood.

Insight into these mechanisms can be gained by studying the highly conserved nuclear hormone receptor (NHR) superfamily. The 48 human NHRs are genetic switches that control networks of genes in response to various physiological cues and orchestrate a diverse range of biological functions, including nutrient homeostasis [1-3]. Typical nuclear receptors are comprised of distinct functional domains, including an $\mathrm{N}$-terminal transactivation domain, a highly conserved DNA-binding domain (DBD) and a C-terminal ligandbinding domain containing a ligand-dependent transactivation 
function [1, 2]. Ligand binding induces a conformational change in the receptor that allows for differential recruitment of cofactors and subsequent modulation of NHR activity [3-6]. A unique feature of many of these receptors is their ability to be activated by lipophilic ligands derived from dietary nutrients such as long chain fatty acids and sterols.

By controlling networks of genes in key metabolic organs, NHRs play critical roles in regulating the metabolism of nutrients in a tissue-specific manner [7]. NHRs also regulate the expression of core clock genes both centrally and peripherally to coordinate and establish daily rhythmicity. Recent studies show that certain members of the fibroblast growth factor (FGF) family are direct targets of NHRs and responsible for mediating many of their metabolic effects. Their importance in metabolism, combined with the ability to manipulate their ligand-dependent activity, make NHRs attractive drug targets for the treatment of metabolic disease. Here, we discuss the roles of NHRs, during feast and famine, in adipose tissue, liver and muscle, as well as their roles in establishing circadian rhythms and regulating FGFs.

\section{Adipose tissue}

White adipose tissue (WAT) is the major energy reserve in mammals. The primary function of WAT is to synthesise and store triacylglycerol during periods of energy excess and to hydrolyse triacylglycerol to generate fatty acids and glycerol for use by other organs during periods of energy deprivation [8]. WAT also secretes adipokines such as leptin and adiponectin that regulate energy intake, metabolism and insulin sensitivity. Excess storage of triacylglycerol in WAT results in obesity and related disorders, including type 2 diabetes. Paradoxically, the metabolic abnormalities found in obesity are also found in lipodystrophies, which are characterised by the inability to properly store fat in adipose tissue. Therefore, an appropriate capacity to store triacylglycerol in WAT in response to changes in nutrient availability is critical for metabolic homeostasis.

While multiple NHRs have been shown to affect WAT metabolism, peroxisome proliferator-activated receptor (PPAR) $\gamma$ is the most critical for proper WAT function [9, 10]. PPAR $\gamma$ is most highly expressed in adipose tissue and is best known for its role in regulating adipogenic and lipogenic pathways. Generation of whole-body and adipose-specific $\operatorname{PPAR} \gamma$ knockout mice revealed that PPAR $\gamma$ is not only required for adipocyte differentiation but also for mature adipocyte function [11-16]. PPAR $\gamma$ also plays a critical role in glucose homeostasis by increasing the expression of GLUT4 and c-Cbl-associated protein, as well as numerous secreted factors that affect insulin sensitivity, such as adiponectin, resistin, leptin and TNF $\alpha$ in WAT [17-20] (Fig. 1a). In mice, activation of PPAR $\gamma$ specifically in adipocytes is sufficient to cause whole-body insulin sensitisation and, conversely, a dominant-negative mutation in a single allele of PPARG in humans leads to partial lipodystrophy and insulin resistance, supporting its role in adipogenesis and insulin sensitivity [21-24]. The thiazolidinediones (TZDs), which are known agonists of PPAR $\gamma$, exhibit potent adipogenic and glucose-lowering effects, and, despite their unwanted side effects, remain highly effective for the treatment of metabolic disease [25].

\section{Liver}

Maintenance of blood glucose level is a primary requirement for survival. Although multiple organs are involved in glucose homeostasis, the liver is the major player. During the fed state, excess glucose is taken up by the liver and stored as glycogen via glycogenesis or converted into fatty acids (de novo lipogenesis) for synthesis/storage as triacylglycerol. During the fasted state, stored glycogen is broken down by the liver to generate glucose by a process called glycogenolysis. Prolonged fasting or starvation induces de novo glucose synthesis in the liver through hepatic gluconeogenesis. During starvation, when glycogen stores are depleted and there is a reliance on fatty acids, the liver also uses acetyl-CoA to produce ketones, by a process termed ketogenesis.

Several NHRs have been implicated in the control of glucose homeostasis in the liver (Fig. 1b). The first NHR to be linked with hepatic gluconeogenesis was the glucocorticoid receptor, which is activated by cortisol. During fasting, increased secretion of cortisol from the adrenal gland increases the activity of the glucocorticoid receptor in the liver, leading to transcriptional activation of hepatic gluconeogenic genes such as glucose-6-phosphatase (G6PC) and phosphoenolpyruvate carboxykinase ( $P E P C K$, also known as $P C K 1)$. Other NHRs, such as hepatocyte nuclear factor 4 (HNF4) and oestrogen-related receptor $\gamma(\mathrm{ERR} \gamma)$ have also been shown to promote hepatic gluconeogenesis during fasting [26, 27]. PPAR $\alpha$ is also critical in the liver during the adaptive response to fasting. PPAR $\alpha$ null mice do not present any overt phenotype under standard animal housing conditions. However, when fasted, they exhibit severe hypoglycaemia and impaired ketogenesis [28-30]. Interestingly, the fatty acid synthasedependent phospholipid 1-palmitoyl-2-oleoyl-sn-glycerol-3phosphocholine (16:0/18:1-GPC) has been shown to be an endogenous ligand for PPAR $\alpha$ [31]. During the fed state, liver $\mathrm{X}$ receptor (LXR) $\alpha$ and $\mathrm{LXR} \beta$, which are activated by oxysterols, have been shown to suppress gluconeogenic enzymes and upregulate the expression of glucokinase to promote hepatic glucose utilisation [32], while the bile acid responsive farnesoid $X$ receptor (FXR) suppresses gluconeogenic genes and increases glycogen synthesis [33]. 
a

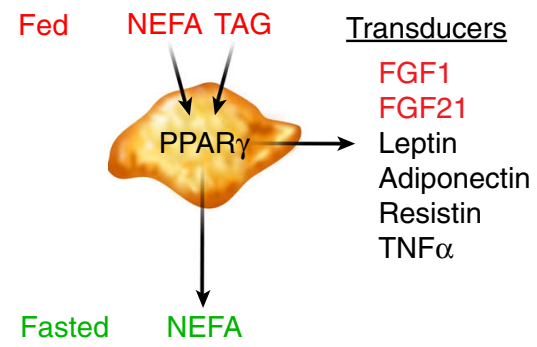

b

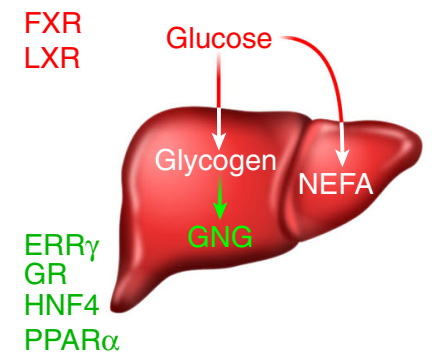

C Glycolytic (II)

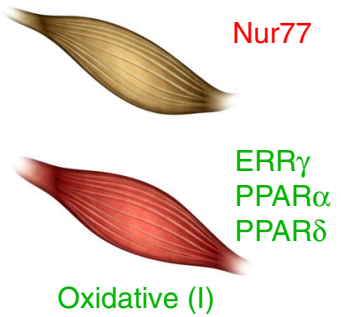

Fig. 1 (a) Adipose tissue during feast and famine. During the fed state, white adipose tissue (WAT) synthesises and stores energy in the form of triacylglycerol (TAG). During the fasted state, WAT hydrolyses TAG to generate NEFA that can be taken up by other organs and used for energy production. Peroxisome proliferator-activated receptor (PPAR) $\gamma$ plays a major role in controlling the expression of genes involved in adipogenesis and lipogenesis. PPAR $\gamma$ also controls the expression of secreted factors (transducers) involved in glucose and energy homeostasis such as leptin, adiponectin, resistin and TNF $\alpha$ as well as fibroblast growth factor (FGF) 1 and FGF21, which act locally in adipose tissue during the fed state to promote adipose remodelling and differentiation, respectively. (b) Liver during feast and famine. During the fed state, excess glucose is taken up by the liver and stored as glycogen via glycogenesis or converted to NEFA through de novo lipogenesis for synthesis and storage as TAG. During the fasted state, glycogen is broken down to generate glucose via glycogenolysis. Prolonged fasting leads to de novo glucose synthesis in the liver through gluconeogenesis (GNG). During starvation, when glycogen stores are depleted, the liver uses acetyl-CoA to produce ketones by a process called ketogenesis, where PPAR $\alpha$ plays an important role. The glucocorticoid receptor (GR), oestrogen-related receptor $\gamma(\mathrm{ERR} \gamma)$ and hepatocyte nuclear factor 4 (HNF4) promote gluconeogenesis, while liver X receptor (LXR) and farnesoid X receptor (FXR) suppress gluconeogenesis. During the fed state, high cholesterol levels activate LXR to promote the production of bile acids. High bile acid levels are then sensed by FXR, which inhibits their synthesis to prevent an accumulation of bile acids in the liver. (c) Skeletal muscle during feast and famine. Type I fibres preferentially oxidise fatty acids, while type II fibres preferentially metabolise glucose. PPAR $\gamma$ and ERR $\gamma$ promote a type I fibre type in skeletal muscle and PPAR $\alpha$ promotes fatty acid utilisation, while Nur77 promotes glucose utilisation
In addition to promoting glucose uptake and storage, the liver plays an important role in cholesterol, bile acid, fatty acid and triacylglycerol homeostasis. When cholesterol levels are high, oxysterols generated through cholesterol degradation activate LXR, which in the liver leads to the formation of bile acids, to avoid excess accumulation of cholesterol. High levels of bile acids are sensed by FXR, which inhibits their synthesis in order to prevent an accumulation of bile acids in the liver. During the fed state, LXR activation also leads to increased triacylglycerol accumulation in the liver by increasing the transcription of genes involved in hepatic de novo lipogenesis [34]. While PPAR $\alpha$ has also been shown to increase the expression of some genes involved in lipogenesis, it also promotes the uptake and oxidation of fatty acids in mitochondria, peroxisomes and microsomes [35]. PPAR $\alpha$ activation leads to lower serum triacylglycerol levels through induction of lipoprotein lipase (LPL) activity via inhibition of apoCIII (LPL inhibitor) expression [35]. In addition to the hypolipidaemic fibrate drugs that target PPAR $\alpha$, it is possible that targeting of other NHRs in the liver may lead to promising therapeutics for the metabolic syndrome.

\section{Muscle}

Skeletal muscle is composed of multiple myofibres that differ in their metabolic properties, including oxidative slow-twitch (type I), mixed oxidative-glycolytic fast-twitch (type IIa) and glycolytic fast-twitch (type IIb) myofibres [36, 37]. Type I fibres preferentially oxidise fatty acids, while type II fibres preferentially metabolise glucose. Adaptation to fasting in skeletal muscle is aimed at sparing glucose by switching to fatty acid oxidation. Suppression of glucose utilisation is accomplished via activation of pyruvate dehydrogenase kinase 4 (PDK4), which phosphorylates and thus inactivates the pyruvate dehydrogenase complex to prevent pyruvate oxidation and conserve lactate and alanine for gluconeogenesis [38]. During the fed state, when insulin levels are high, skeletal muscle handles the majority of glucose disposal in the body.

NHRs play a critical role in controlling glucose and fatty acid metabolism in skeletal muscle (Fig. 1c). Growth factorinducible immediate early gene nur/77-like receptor (Nur77), a NHR preferentially expressed in glycolytic vs oxidative muscle, promotes the expression of genes involved in glucose metabolism in skeletal muscle [39]. On the other hand, PPAR $\alpha$, which activates PDK4, promotes lipid utilisation and inhibits glucose uptake in skeletal muscle [38, 40]. Mice overexpressing PPAR $\alpha$ in skeletal muscle exhibit glucose intolerance but are protected from high fat diet (HFD)-induced obesity, while PPAR $\alpha$ null mice exhibit enhanced glucose tolerance, despite increased triacylglycerol accumulation in muscle and HFD-induced obesity [40]. PPAR $\delta$ also promotes fatty acid utilisation in muscle but, in contrast to PPAR $\alpha$, activation of PPAR $\delta$ leads to enhanced glucose uptake and improved skeletal muscle insulin sensitivity, as evidenced by studies in mice with genetic ablation and ectopic expression of $\operatorname{PPAR} \delta[28,41-44]$. PPAR $\delta$ has also been shown to activate a genetic programme that induces a type I endurance muscle fibre type switch, leading to an enhanced capacity for 
endurance running and the ability to oxidise both lipids and carbohydrates at higher rates [42]. In this regard, ERR $\gamma$, which is expressed at much higher levels in type I vs type II muscle fibres, has been shown to be critical for maintaining the highly vascularised and oxidative capacity of type I muscle fibres, even in the absence of exercise [45]. This ability to manipulate oxidative/glycolytic metabolism in skeletal muscle through NHRs represents a potential therapeutic avenue for treating metabolic disease [46].

\section{Circadian rhythms}

Mammals experience natural sleep/wake and fed/fasted cycles and most physiological processes are regulated in a circadian manner. These rhythms are generated by a master clock located in the suprachiasmatic nucleus (SCN) of the hypothalamus, which synchronises physiology to day/night cycles. While the master clock, which is entrained by light onto the retina, can synchronise clocks in peripheral tissues, feeding/fasting rhythms also serve as strong entrainment factors for metabolic organs.

At the genomic level, NHR signalling is intertwined with the core clock machinery, which consists of the transcription factors circadian locomotor output cycles kaput (CLOCK) and brain and muscle ARNT-like 1 (BMAL1) and their corepressors period (PER) and cryptochrome (CRY). NHRs can be regulated by the clock and can also regulate the clock themselves. The NHRs reverse c-erbA (REV-ERB) $\alpha$ and REV-ERB $\beta$ along with three retinoid orphan receptors $(\operatorname{ROR} \alpha, \beta, \gamma)$ regulate many metabolic pathways in a circadian fashion by binding to target genes with an ROR response element. These receptors reciprocally regulate the expression of target genes, with RORs serving as constitutive activators and REV-ERBs acting as repressors [47] (Fig. 2). The

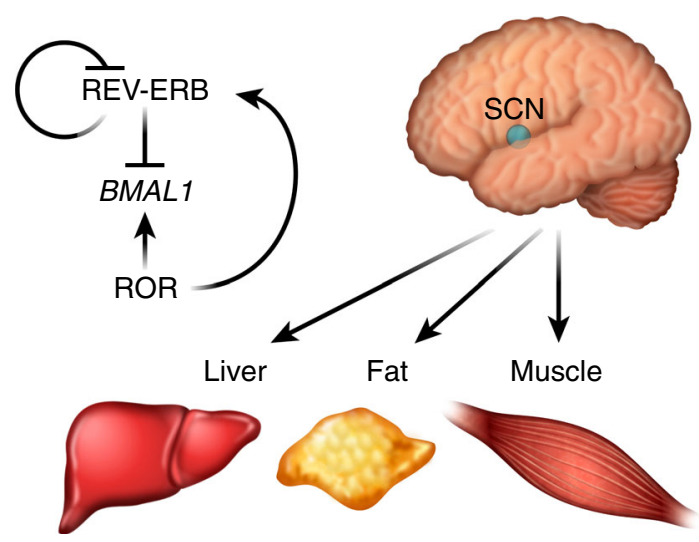

Fig. 2 Circadian metabolism. Circadian rhythms are generated by a master clock located in the SCN of the hypothalamus, which is entrained by light on the retina and can synchronise the clocks in peripheral tissues. Feeding/fasting cues also serve as strong entrainment factors for metabolic organs. REV-ERBs and RORs reciprocally regulate the expression of target genes, including BMAL1. REV-ERBs act as transcriptional repressors, while RORs act as activators circadian expression pattern of BMAL1 is generated by the oscillating expression of both ROR $\alpha$ and REV-ERB $\alpha$ in the $\mathrm{SCN}$ [48]. REV-ERB $\alpha$ and REV-ERB $\beta$ are also involved in peripheral circadian regulation of liver metabolism by regulating the CLOCK-BMAL1 transcriptomes [49]. Interestingly, haem has been identified as an endogenous ligand for REV-ERB $\alpha / \beta$ linking metabolism and circadian clock [50, 51]. Furthermore, many genes involved in both clock and metabolic functions harbour BMAL1 and REV-ERB $\alpha / \beta$ binding sites, indicating an integrated mechanism of circadian gene expression by these transcription factors [49, 52].

The glucocorticoid receptor also plays a critical role in establishing circadian rhythmicity [53]. Circulating levels of glucocorticoids oscillate throughout the day with peak levels during the onset of activity. The glucocorticoid receptor is also critical for resetting the clock in peripheral tissues, such as the liver, and there are glucocorticoid response elements (GREs) in core clock genes such as PER1 and PER2. It has also been shown that CRY directly binds to the glucocorticoid receptor to regulate its activity. In addition to the glucocorticoid receptor, REV-ERB $\alpha / \beta$ and RORs, many other NHRs have been shown to be expressed in a circadian fashion and play a role in circadian metabolism $[54,55]$. In fact, in key metabolic organs such liver, muscle and adipose tissue, over half of the NHRs detected exhibit circadian expression, suggesting that changes in the expression of NHRs and their downstream target genes are likely to explain the cyclical behaviour of glucose and lipid metabolism [55].

\section{The NHR-FGF connection}

Recently, NHRs have been shown to exert control on nutritional homeostasis by regulating the expression of four different members of the FGF family $[25,56]$. FGFs are secreted heparan sulphate-binding proteins that act locally by signalling through FGF receptors and are typically involved in cell growth, angiogenesis and wound healing [57, 58]. In contrast, the endocrine FGFs (FGF 19, 21 and 23) have poor affinity for heparan sulphate and therefore circulate rather than being immobilised in the extracellular matrix [58]. While the classical, paracrine FGFs require heparan sulphate for proper activation of FGF receptors, the endocrine FGFs require the $\alpha$ or $\beta$ Klotho co-receptors for signalling [56, 59]. The endocrine FGFs have received much attention for their role as metabolic regulators and are controlled by NHRs (Fig. 1a). While FGF23, through its interaction with the vitamin $\mathrm{D}$ receptor, has been shown to be critical for controlling vitamin D metabolism, we will focus on the FXR-FGF19 and PPAR-FGF21 signalling pathways because of their relevance during feast and famine [56] (Fig. 3).

FGF19 is a postprandial hormone, and the gene encoding this FGF is a direct bile acid-dependent target of FXR. The 
Fig. 3 NHR-FGF interface during feast and famine. During the fed state PPAR $\gamma$, which is activated by fatty acids, increases the expression of both FGF1 and FGF21 to promote adipose remodelling and adipocyte differentiation, respectively. During the fed state, bile acids activate FXR, which increases the expression of FGF15/19 to promote bile acid homeostasis. During the fasted state, fatty acids activate $\operatorname{PPAR} \alpha$ to control energy homeostasis

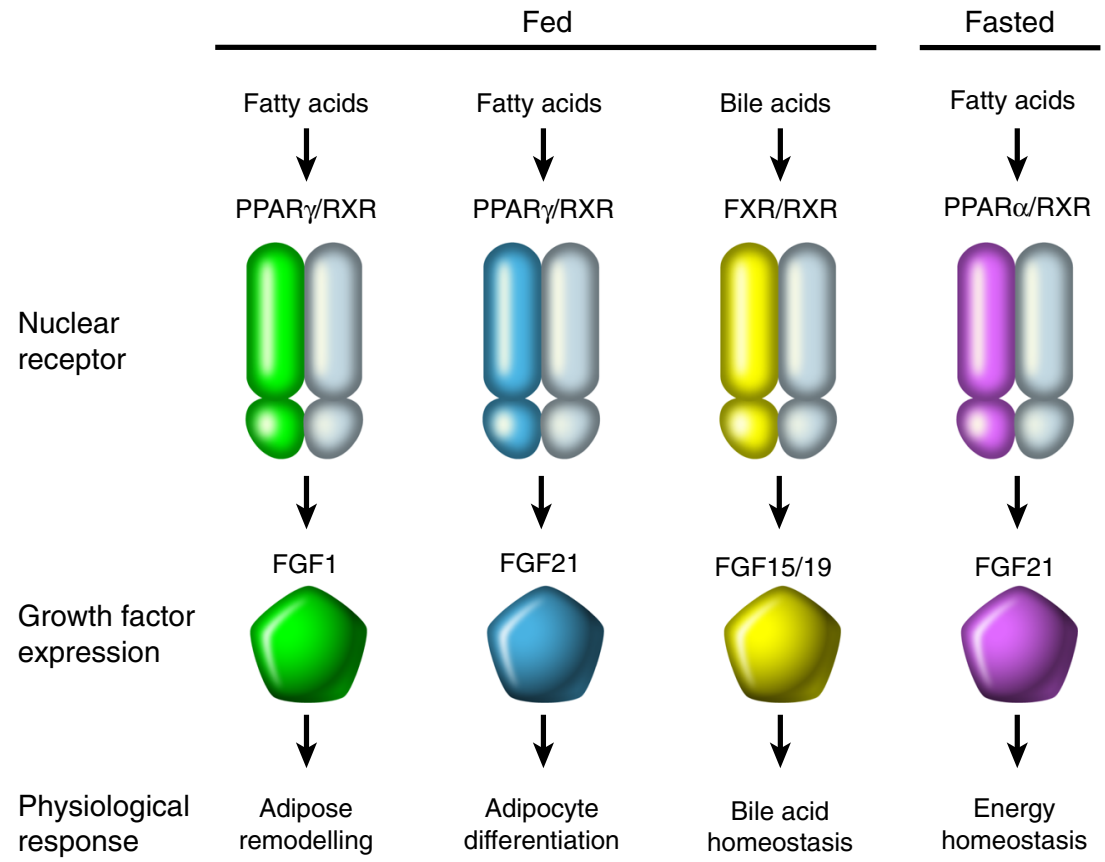

importance of FGF19 (FGF15 in rodents) in maintaining bile homeostasis has been demonstrated in both rodent studies and human clinical studies. In addition to its importance in bile acid metabolism, FGF19 has also been shown to lower blood glucose, hepatic triacylglycerol and cholesterol levels [60, 61] and induce protein and glycogen synthesis in the liver independently of insulin [62]. However, unlike insulin, FGF19 does not activate the phosphoinositide 3-kinase (PI3K)-Akt signalling pathway but, rather, signals through the Ras-extracellular signal-related kinase (ERK) pathway to promote protein and glycogen synthesis [62, 63]. FGF19 also reduces hepatic gluconeogenesis by repressing the expression of the transcription cofactor PPAR $\gamma$ co-activator $1 \alpha(\mathrm{PGC} 1 \alpha)$, and the PGC $1 \alpha$ target genes, G6PC and PEPCK, also through a mechanism distinct from that of insulin [64]. Unlike insulin, FGF19 does not increase lipogenesis and actually, as mentioned above, reduces hepatic triacylglycerol and cholesterol levels $[60,61]$. While there are concerns regarding potential mitogenic effects $[65,66]$, its overlapping but unique functions with insulin make FGF19 an attractive target for the treatment of both type 1 and 2 diabetes.

In addition to FGF19, FGF21 has emerged as a member of the endocrine FGFs that is regulated by an NHR to control metabolism. Initially identified as a factor induced by PPAR $\alpha$ in the liver in response to fasting, FGF21 is now recognised as a key player in the adaptive starvation response, helping to shift hepatic metabolism from carbohydrates to fatty acids and ketone bodies [67, 68]. Interestingly, FGF21 also has an important function in the fed state, where it is induced by PPAR $\gamma$ and works in a paracrine manner in adipose tissue to enhance adipogenesis $[68,69]$. FGF21 knockout mice exhibit impaired PPAR $\gamma$ signalling in adipose tissue, reduced adiposity and are resistant to the insulin-sensitising effects, as well as the undesirable side effects, of the TZDs, which, as mentioned previously, are PPAR $\gamma$ agonists [67]. Pharmacological administration of FGF21 reverses hepatic steatosis and improves glucose homeostasis in rodents and non-human primates [70-72]. Recent studies have shown that FGF21 exerts its effects on glucose homeostasis through adiponectin, an adipokine known to enhance insulin sensitivity [73, 74]. It remains to be determined whether other metabolic effects of FGF21 are also mediated through adiponectin. In addition to its effects on peripheral metabolism, FGF21 was recently shown to act centrally to promote adaptations to fasting by increasing glucocorticoid levels, suppressing physical activity and altering circadian behaviour [75]. Prevention of female reproduction is a critical adaptation to starvation, and FGF21 has been shown to exert an inhibitory effect on this process by acting on the SCN in the hypothalamus [76]. Future studies further addressing how the central and peripheral actions of FGF21 are coordinated to control metabolism will be an exciting new avenue of research [75, 76].

While the endocrine family of FGFs has received the most attention for its role in metabolism, a new role for the nonendocrine FGF1 in nutrient homeostasis has emerged. As part of a screen to identify genes that respond to feast and famine cues, FGF1 was found to be induced in WAT in response to HFD and repressed during a fast, pointing to an unexpected metabolic function in both fed-state and fasted-state responses. FGF1 was also shown to be induced in visceral adipose tissue in response to HFD or TZD treatment [77]. Despite its implication in multiple physiological processes, 
FGF1 knockout mice exhibit no phenotype under standard laboratory conditions, which led to the long-held assumption that it was dispensable [58]. However, when placed on an HFD, FGF1 knockout mice develop marked fibrosis in adipose tissue, structurally restricting adipose tissue expansion and resulting in a severe diabetic phenotype. Even more striking, upon withdrawal of the HFD the adipose tissue in these mice fails to properly contract, leading to severe necrosis of the adipose tissue [77]. The induction of FGF1 expression in adipose tissue in the fed state is regulated at the genomic level by PPAR $\gamma$, identifying a PPAR $\gamma$-FGF1 signalling axis crucial for handling cycles of feast and famine.

\section{Concluding remarks}

As global regulators of metabolism, NHRs play critical roles in key metabolic organs during feast and famine. Their importance in metabolism, combined with their ability to be modulated by small lipophilic ligands, make NHRs one of the most highly therapeutically targeted protein families, serving as targets for drugs including glucocorticoids, thyroid hormone, tamoxifen, fibrates and TZDs. Although these NHR-targeted drugs are highly effective, there is the potential to improve on some of these therapies. For example, while highly effective for treating type 2 diabetes, TZDs are accompanied by unwanted side effects, including fluid retention, weight gain, bone loss and congestive heart failure. New strategies are being developed for improving TZD-based therapies, one of which involves targeting downstream effectors of PPAR $\gamma$, such as FGF21 or, potentially, FGF1. In this regard, it will be important to dissect the relative roles of these two FGFs in adipose tissue, since they are both regulated in the fed state by PPAR $\gamma$. Recently, a FGF21 analogue has been shown to improve dyslipidaemia in obese people, however only a trend toward glucose lowering was observed [78, 79]. Also, bone loss in these individuals was not examined, which will be important since FGF21 causes bone loss in rodents [80]. While drugs are being developed for FGF21, it will be interesting to see what effect, if any, FGF1 has systemically. Also, the insulin-like properties of FGF19, combined with its ability to lower triacylglycerol and cholesterol levels and its nonlipogenic properties, make it an attractive therapeutic target of the treatment of both type 1 and 2 diabetes. While there are concerns about potential mitogenic effects of FGF19 [65, 66], therapies designed to dissociate its mitogenic effects from its metabolic ones might be possible [81]. Additionally, targeting NHRs that affect circadian metabolism might be an interesting therapeutic avenue. In this regard, compounds that act as agonists for REV-ERBs have been suggested to modulate the circadian clock and improve metabolic defects in mice $[82,83]$. As our knowledge of NHR action in nutrient homeostasis continues to advance, these critical integrators of metabolism remain promising therapeutic targets for the treatment of metabolic disease.

Acknowledgements We thank L. Ong and C. Brondos from the Salk Institute for administrative assistance.

Funding RME is an Investigator of the Howard Hughes Medical Institute at the Salk Institute and March of Dimes Chair in Molecular and Developmental Biology. This work was supported by US National Institutes of Health grants (DK057978, DK090962, HL088093, HL105278, CA014195 and ES010337), the Glenn Foundation for Medical Research, the Leona M. and Harry B. Helmsley Charitable Trust, Ipsen/Biomeasure, and the Ellison Medical Foundation. MA is supported by an F32 Ruth L. Kirschstein National Research Service Award (National Institute of Diabetes and Digestive and Kidney Diseases).

Duality of interest The authors declare that there is no duality of interest associated with this manuscript.

Contribution statement S-HH, MA, RTY, ARA, MD and RME were responsible for the conception and drafting of the manuscript, and are responsible for the intellectual content and approved the final version.

Open Access This article is distributed under the terms of the Creative Commons Attribution License which permits any use, distribution, and reproduction in any medium, provided the original author(s) and the source are credited.

\section{References}

1. Chambon P (2005) The nuclear receptor superfamily: a personal retrospect on the first two decades. Mol Endocrinol 19:1418-1428

2. Mangelsdorf DJ, Thummel C, Beato $M$ et al (1995) The nuclear receptor superfamily: the second decade. Cell 83:835-839

3. Privalsky ML (2004) The role of corepressors in transcriptional regulation by nuclear hormone receptors. Annu Rev Physiol 66:315-360

4. Chen H, Tini M, Evans RM (2001) HATs on and beyond chromatin. Curr Opin Cell Biol 13:218-224

5. Nagy L, Kao HY, Love JD et al (1999) Mechanism of corepressor binding and release from nuclear hormone receptors. Genes Dev 13: 3209-3216

6. Kapoor A, Goldberg MS, Cumberland LK et al (2010) The histone variant macroH2A suppresses melanoma progression through regulation of CDK8. Nature 468:1105-1109

7. Evans RM, Barish GD, Wang YX (2004) PPARs and the complex journey to obesity. Nat Med 10:355-361

8. Ahmadian M, Duncan RE, Jaworski K, Sarkadi-Nagy E, Sul HS (2007) Triacylglycerol metabolism in adipose tissue. Future Lipidol 2:229-237

9. Tontonoz P, Spiegelman BM (2008) Fat and beyond: the diverse biology of PPAR $\gamma$. Annu Rev Biochem 77:289-312

10. Forman BM, Chen J, Evans RM (1996) The peroxisome proliferatoractivated receptors: ligands and activators. Ann N Y Acad Sci 804: 266-275

11. Barak Y, Nelson MC, Ong ES et al (1999) PPAR $\gamma$ is required for placental, cardiac, and adipose tissue development. Mol Cell 4:585-595

12. Imai T, Takakuwa R, Marchand S et al (2004) Peroxisome proliferatoractivated receptor $\gamma$ is required in mature white and brown adipocytes for their survival in the mouse. Proc Natl Acad Sci U S A 101:4543-4547

13. He W, Barak Y, Hevener A et al (2003) Adipose-specific peroxisome proliferator-activated receptor $\gamma$ knockout causes insulin resistance in 
fat and liver but not in muscle. Proc Natl Acad Sci U S A 100:1571215717

14. Wang F, Mullican SE, DiSpirito JR, Peed LC, Lazar MA (2013) Lipoatrophy and severe metabolic disturbance in mice with fatspecific deletion of PPAR $\gamma$. Proc Natl Acad Sci U S A 110:1865618661

15. Kershaw EE, Schupp M, Guan HP, Gardner NP, Lazar MA, Flier JS (2007) PPAR $\gamma$ regulates adipose triglyceride lipase in adipocytes in vitro and in vivo. Am J Physiol Endocrinol Metab 293:E1736-E1745

16. Rodriguez-Cuenca S, Carobbio S, Velagapudi VR et al (2012) Peroxisome proliferator-activated receptor $\gamma$-dependent regulation of lipolytic nodes and metabolic flexibility. Mol Cell Biol 32:1555-1565

17. Hollenberg AN, Susulic VS, Madura JP et al (1997) Functional antagonism between CCAAT/Enhancer binding protein- $\alpha$ and peroxisome proliferator-activated receptor- $\gamma$ on the leptin promoter. J Biol Chem 272:5283-5290

18. Iwaki M, Matsuda M, Maeda N et al (2003) Induction of adiponectin, a fat-derived antidiabetic and antiatherogenic factor, by nuclear receptors. Diabetes 52:1655-1663

19. Hofmann C, Lorenz K, Braithwaite SS et al (1994) Altered gene expression for tumor necrosis factor- $\alpha$ and its receptors during drug and dietary modulation of insulin resistance. Endocrinology 134: 264-270

20. Tomaru T, Steger DJ, Lefterova MI, Schupp M, Lazar MA (2009) Adipocyte-specific expression of murine resistin is mediated by synergism between peroxisome proliferator-activated receptor $\gamma$ and CCAAT/enhancer-binding proteins. J Biol Chem 284:6116-6125

21. Agarwal AK, Garg A (2002) A novel heterozygous mutation in peroxisome proliferator-activated receptor- $\gamma$ gene in a patient with familial partial lipodystrophy. J Clin Endocrinol Metab 87:408-411

22. Hegele RA, Cao H, Frankowski C, Mathews ST, Leff T (2002) $P P A R G$ F $388 \mathrm{~L}$, a transactivation-deficient mutant, in familial partial lipodystrophy. Diabetes 51:3586-3590

23. Savage DB, Tan GD, Acerini CL et al (2003) Human metabolic syndrome resulting from dominant-negative mutations in the nuclear receptor peroxisome proliferator-activated receptor- $\gamma$. Diabetes 52: 910-917

24. Sugii S, Olson P, Sears DD et al (2009) PPAR $\gamma$ activation in adipocytes is sufficient for systemic insulin sensitization. Proc Natl Acad Sci U S A 106:22504-22509

25. Ahmadian M, Suh JM, Hah N et al (2013) PPAR $\gamma$ signaling and metabolism: the good, the bad and the future. Nat Med 19:557-566

26. Rhee J, Inoue Y, Yoon JC et al (2003) Regulation of hepatic fasting response by PPAR $\gamma$ coactivator- $1 \alpha$ (PGC-1): requirement for hepatocyte nuclear factor $4 \alpha$ in gluconeogenesis. Proc Natl Acad Sci U S A 100:4012-4017

27. Kim DK, Gang GT, Ryu D et al (2013) Inverse agonist of nuclear receptor ERR $\gamma$ mediates antidiabetic effect through inhibition of hepatic gluconeogenesis. Diabetes 62:3093-3102

28. Muoio DM, MacLean PS, Lang DB et al (2002) Fatty acid homeostasis and induction of lipid regulatory genes in skeletal muscles of peroxisome proliferator-activated receptor (PPAR) alpha knock-out mice. Evidence for compensatory regulation by PPAR $\delta$. J Biol Chem 277:26089-26097

29. Leone TC, Weinheimer CJ, Kelly DP (1999) A critical role for the peroxisome proliferator-activated receptor $\alpha(\operatorname{PPAR} \alpha)$ in the cellular fasting response: the PPAR $\alpha$-null mouse as a model of fatty acid oxidation disorders. Proc Natl Acad Sci U S A 96:7473-7478

30. Kersten S, Seydoux J, Peters JM, Gonzalez FJ, Desvergne B, Wahli W (1999) Peroxisome proliferator-activated receptor alpha mediates the adaptive response to fasting. J Clin Invest 103:1489-1498

31. Chakravarthy MV, Lodhi IJ, Yin L et al (2009) Identification of a physiologically relevant endogenous ligand for PPAR $\alpha$ in liver. Cell 138:476- 488

32. Laffitte BA, Chao LC, Li J et al (2003) Activation of liver X receptor improves glucose tolerance through coordinate regulation of glucose metabolism in liver and adipose tissue. Proc Natl Acad Sci U S A 100:5419-5424

33. Zhang Y, Lee FY, Barrera G et al (2006) Activation of the nuclear receptor FXR improves hyperglycemia and hyperlipidemia in diabetic mice. Proc Natl Acad Sci U S A 103:1006-1011

34. Grefhorst A, Elzinga BM, Voshol PJ et al (2002) Stimulation of lipogenesis by pharmacological activation of the liver $\mathrm{X}$ receptor leads to production of large, triglyceride-rich very low density lipoprotein particles. J Biol Chem 277:34182-34190

35. Burri L, Thoresen GH, Berge RK (2010) The role of PPAR $\alpha$ activation in liver and muscle. PPAR Res. doi:10.1155/2010/542359

36. Fluck M, Hoppeler H (2003) Molecular basis of skeletal muscle plasticity - from gene to form and function. Rev Physiol Biochem Pharmacol 146:159-216

37. Pette D, Staron RS (2000) Myosin isoforms, muscle fiber types, and transitions. Microsc Res Tech 50:500-509

38. Wu P, Peters JM, Harris RA (2001) Adaptive increase in pyruvate dehydrogenase kinase 4 during starvation is mediated by peroxisome proliferator-activated receptor $\alpha$. Biochem Biophys Res Commun 287:391-396

39. Chao LC, Zhang Z, Pei L, Saito T, Tontonoz P, Pilch PF (2007) Nur77 coordinately regulates expression of genes linked to glucose metabolism in skeletal muscle. Mol Endocrinol 21:2152-2163

40. Finck BN, Bernal-Mizrachi C, Han DH et al (2005) A potential link between muscle peroxisome proliferator-activated receptor-alpha signaling and obesity-related diabetes. Cell Metab 1:133-144

41. Narkar VA, Downes M, Yu RT et al (2008) AMPK and PPAR $\delta$ agonists are exercise mimetics. Cell 134:405-415

42. Wang YX, Zhang CL, Yu RT et al (2004) Regulation of muscle fiber type and running endurance by PPAR $\delta$. PLoS Biol 2:e294

43. Schuler M, Ali F, Chambon C et al (2006) PGC1 $\alpha$ expression is controlled in skeletal muscles by PPAR $\beta$, whose ablation results in fiber-type switching, obesity, and type 2 diabetes. Cell Metab 4:407414

44. Tanaka T, Yamamoto J, Iwasaki S et al (2003) Activation of peroxisome proliferator-activated receptor $\delta$ induces fatty acid $\beta$-oxidation in skeletal muscle and attenuates metabolic syndrome. Proc Natl Acad Sci U S A 100:15924-15929

45. Narkar VA, Fan W, Downes M et al (2011) Exercise and PGC-1 $\alpha$ independent synchronization of type I muscle metabolism and vasculature by ERR $\gamma$. Cell Metab 13:283-293

46. Egan B, Zierath JR (2013) Exercise metabolism and the molecular regulation of skeletal muscle adaptation. Cell Metab 17:162-184

47. Guillaumond F, Dardente H, Giguere V, Cermakian N (2005) Differential control of Bmall circadian transcription by REV-ERB and ROR nuclear receptors. J Biol Rhythm 20:391-403

48. Sato TK, Panda S, Miraglia LJ et al (2004) A functional genomics strategy reveals Rora as a component of the mammalian circadian clock. Neuron 43:527-537

49. Cho H, Zhao X, Hatori M et al (2012) Regulation of circadian behaviour and metabolism by REV-ERB- $\alpha$ and REV-ERB- $\beta$. Nature 485:123-127

50. Yin L, Wu N, Curtin JC et al (2007) Rev-erb $\alpha$, a heme sensor that coordinates metabolic and circadian pathways. Science 318:17861789

51. Raghuram S, Stayrook KR, Huang P et al (2007) Identification of heme as the ligand for the orphan nuclear receptors REV-ERB $\alpha$ and REV-ERB $\beta$. Nat Struct Mol Biol 14:1207-1213

52. Bugge A, Feng D, Everett LJ et al (2012) Rev-erbalpha and Rev-erb $\beta$ coordinately protect the circadian clock and normal metabolic function. Genes Dev 26:657-667

53. Lamia KA, Papp SJ, Yu RT et al (2011) Cryptochromes mediate rhythmic repression of the glucocorticoid receptor. Nature 480:552556

54. Gachon F, Leuenberger N, Claudel T et al (2011) Proline- and acidic amino acid-rich basic leucine zipper proteins modulate 
peroxisome proliferator-activated receptor $\alpha$ (PPAR $\alpha)$ activity. Proc Natl Acad Sci U S A 108:4794-4799

55. Yang X, Downes M, Yu RT et al (2006) Nuclear receptor expression links the circadian clock to metabolism. Cell 126:801-810

56. Angelin B, Larsson TE, Rudling M (2012) Circulating fibroblast growth factors as metabolic regulators - a critical appraisal. Cell Metab 16:693-705

57. Goetz R, Mohammadi M (2013) Exploring mechanisms of FGF signalling through the lens of structural biology. Nat Rev Mol Cell Biol 14:166-180

58. Beenken A, Mohammadi M (2009) The FGF family: biology, pathophysiology and therapy. Nat Rev Drug Discov 8:235-253

59. Ding X, Boney-Montoya J, Owen BM et al (2012) $\beta$ Klotho is required for fibroblast growth factor 21 effects on growth and metabolism. Cell Metab 16:387-393

60. Tomlinson E, Fu L, John L et al (2002) Transgenic mice expressing human fibroblast growth factor-19 display increased metabolic rate and decreased adiposity. Endocrinology 143:1741-1747

61. Fu L, John LM, Adams SH et al (2004) Fibroblast growth factor 19 increases metabolic rate and reverses dietary and leptin-deficient diabetes. Endocrinology 145:2594-2603

62. Kir S, Beddow SA, Samuel VT et al (2011) FGF19 as a postprandial, insulin-independent activator of hepatic protein and glycogen synthesis. Science 331:1621-1624

63. Kir S, Kliewer SA, Mangelsdorf DJ (2011) Roles of FGF19 in liver metabolism. Cold Spring Harb Symp Quant Biol 76:139-144

64. Potthoff MJ, Boney-Montoya J, Choi M et al (2011) FGF15/19 regulates hepatic glucose metabolism by inhibiting the CREB-PGC-1 $\alpha$ pathway. Cell Metab 13:729-738

65. Ho HK, Pok S, Streit S et al (2009) Fibroblast growth factor receptor 4 regulates proliferation, anti-apoptosis and $\alpha$-fetoprotein secretion during hepatocellular carcinoma progression and represents a potential target for therapeutic intervention. J Hepatol 50: $118-127$

66. Nicholes K, Guillet S, Tomlinson E et al (2002) A mouse model of hepatocellular carcinoma: ectopic expression of fibroblast growth factor 19 in skeletal muscle of transgenic mice. Am J Pathol 160: 2295-2307

67. Dutchak PA, Katafuchi T, Bookout AL et al (2012) Fibroblast growth factor-21 regulates PPAR $\gamma$ activity and the antidiabetic actions of thiazolidinediones. Cell 148:556-567

68. Badman MK, Pissios P, Kennedy AR, Koukos G, Flier JS, Maratos-Flier E (2007) Hepatic fibroblast growth factor 21 is regulated by PPAR $\alpha$ and is a key mediator of hepatic lipid metabolism in ketotic states. Cell Metab 5:426-437
69. Inagaki T, Dutchak P, Zhao G et al (2007) Endocrine regulation of the fasting response by PPAR $\alpha$-mediated induction of fibroblast growth factor 21. Cell Metab 5:415-425

70. Xu J, Lloyd DJ, Hale C et al (2009) Fibroblast growth factor 21 reverses hepatic steatosis, increases energy expenditure, and improves insulin sensitivity in diet-induced obese mice. Diabetes 58: 250-259

71. Kharitonenkov A, Wroblewski VJ, Koester A et al (2007) The metabolic state of diabetic monkeys is regulated by fibroblast growth factor-21. Endocrinology 148:774-781

72. Emanuelli B, Vienberg SG, Smyth G et al (2014) Interplay between FGF21 and insulin action in the liver regulates metabolism. $\mathrm{J}$ Clin Invest 124:515-527

73. Lin Z, Tian H, Lam KS et al (2013) Adiponectin mediates the metabolic effects of FGF21 on glucose homeostasis and insulin sensitivity in mice. Cell Metab 17:779-789

74. Holland WL, Adams AC, Brozinick JT et al (2013) An FGF21adiponectin-ceramide axis controls energy expenditure and insulin action in mice. Cell Metab 17:790-797

75. Bookout AL, de Groot MH, Owen BM et al (2013) FGF21 regulates metabolism and circadian behavior by acting on the nervous system. Nat Med 19:1147-1152

76. Owen BM, Bookout AL, Ding X et al (2013) FGF21 contributes to neuroendocrine control of female reproduction. Nat Med 19:1153-1156

77. Jonker JW, Suh JM, Atkins AR et al (2012) A PPAR $\gamma$-FGF1 axis is required for adaptive adipose remodelling and metabolic homeostasis. Nature 485:391-394

78. Gaich G, Chien JY, Fu H et al (2013) The effects of LY2405319, an FGF21 analog, in obese human subjects with type 2 diabetes. Cell Metab 18:333-340

79. Reitman ML (2013) FGF21 mimetic shows therapeutic promise. Cell Metab 18:307-309

80. Wei W, Dutchak PA, Wang X et al (2012) Fibroblast growth factor 21 promotes bone loss by potentiating the effects of peroxisome proliferator-activated receptor gamma. Proc Natl Acad Sci U S A 109:3143-3148

81. Wu AL, Kolumam G, Stawicki S et al (2011) Amelioration of type 2 diabetes by antibody-mediated activation of fibroblast growth factor receptor 1. Sci Trans Med 3:113-126

82. Woldt E, Sebti Y, Solt LA et al (2013) Rev-erb-alpha modulates skeletal muscle oxidative capacity by regulating mitochondrial biogenesis and autophagy. Nat Med 19:1039-1046

83. Solt LA, Wang Y, Banerjee S et al (2012) Regulation of circadian behaviour and metabolism by synthetic REV-ERB agonists. Nature 485:62-68 